\title{
Active smoking and COPD phenotype: distribution and impact on prognostic factors
}

\author{
This article was published in the following Dove Press journal: \\ International Journal of COPD \\ 6 July 2017 \\ Number of times this article has been viewed
}

\author{
Juan Antonio Riesco ${ }^{1,2}$ \\ Bernardino Alcázar ${ }^{3}$ \\ Juan Antonio Trigueros ${ }^{4}$ \\ Anna Campuzano ${ }^{5}$ \\ Joselín Pérez ${ }^{5}$ \\ José Luis Lorenzo 5
}

'Pulmonology Department, Hospital San Pedro de Alcántara, ${ }^{2}$ Centro de Investigación en Red de Enfermedades Respiratorias (CIBERES), Cáceres, ${ }^{3}$ Pulmonology Department, Hospital La Loja, Granada, ${ }^{4}$ Centro de Salud de Menasalvas, Toledo, ${ }^{5} \mathrm{Grupo}$ Ferrer Internacional, Barcelona, Spain
Purpose: Smoking can affect both the phenotypic expression of COPD and factors such as disease severity, quality of life, and comorbidities. Our objective was to evaluate if the impact of active smoking on these factors varies according to the disease phenotype.

Patients and methods: This was a Spanish, observational, cross-sectional, multicenter study of patients with a diagnosis of COPD. Smoking rates were described among four different phenotypes (non-exacerbators, asthma-COPD overlap syndrome [ACOS], exacerbators with emphysema, and exacerbators with chronic bronchitis), and correlated with disease severity (body mass index, obstruction, dyspnea and exacerbations [BODEx] index and dyspnea grade), quality of life according to the COPD assessment test (CAT), and presence of comorbidities, according to phenotypic expression.

Results: In total, 1,610 patients were recruited, of whom $46.70 \%$ were classified as nonexacerbators, $14.53 \%$ as ACOS, $16.37 \%$ as exacerbators with emphysema, and $22.40 \%$ as exacerbators with chronic bronchitis. Smokers were predominant in the latter 2 groups $(58.91 \%$ and $57.67 \%$, respectively, $P=0.03$ ). Active smoking was significantly associated with better quality of life and a higher dyspnea grade, although differences were observed depending on clinical phenotype.

Conclusion: Active smoking is more common among exacerbator phenotypes and appears to affect quality of life and dyspnea grade differently, depending on the clinical expression of the disease.

Keywords: COPD, phenotype, smoking, prognostic factors, quality of life

\section{Introduction}

COPD is characterized by chronic airflow limitation, which is not fully reversible, generally progressive, and associated with an inflammatory pulmonary response to toxic particles and gases. The systemic impact is severe. ${ }^{1}$ This disease presents in a wide variety of forms, and the concept that distinct COPD phenotypes can be identified, each with its characteristic clinical, prognostic, and therapeutic impact, is well established. ${ }^{2}$ In Spain, the GesEPOC guidelines (Spanish COPD guidelines published by the Spanish Society of Pulmonology and Thoracic Surgery, which aim to establish standard recommendations for the management of the disease in Spain) propose 4 phenotypes, each with a different prognosis and therapeutic approach: the non-exacerbator phenotype (with emphysema or chronic bronchitis); the asthmaCOPD overlap syndrome (ACOS); the exacerbator phenotype with emphysema; and the exacerbator phenotype with chronic bronchitis. ${ }^{3}$

Tobacco use is widely accepted as the major risk factor for the development of COPD. ${ }^{4}$ Exposure to tobacco smoke may also act as a differential factor in the various phenotypic expressions of the disease, and evidence suggests that a phenotype derived
Correspondence: Juan Antonio Riesco Pulmonology Department, Hospital San Pedro de Alcántara, Ronda de San Francisco, 19, 10002 Cáceres, Spain Tel +34 927256352

Fax +34 927256202

Email jantonio.riesco@gmail.com (c) (1) (5) 2017 Riesco et al. This work is published and licensed by Dove Medical Press Limited. The full terms of this license are available at https://www.dovepress.com/terms.php cc) hereby accept the Terms. Non-commercial uses of the work are permitted without any further permission from Dove Medical Press Limited, provided the work is properly attributed. For permission for commercial use of this work, please see paragraphs 4.2 and 5 of our Terms (https://www.dovepress.com/terms.php). 
from smoking may be different from one caused by other environmental factors. ${ }^{5-7}$ Active smoking has been associated with COPD severity, quality of life, and comorbidities, although some results are controversial. For example, some authors report a positive relationship between active smoking and a higher rate of admission due to acute exacerbation, but others have not confirmed this finding. ${ }^{8-11}$ The impact of smoking on patients' quality of life has also been a topic of discussion, ${ }^{12-17}$ with previous reports indicating a lower mental $^{13,14}$ and physical ${ }^{16}$ functional status in current smokers and an improvement of health-related quality of life after smoking cessation, ${ }^{15,17}$ although other studies have shown the opposite results. ${ }^{18,19}$

The primary objective of this study, conducted under the auspices of a large trial aimed primarily at describing the distribution and characteristics of the different COPD phenotypes in Spain, was to examine the cross-sectional prevalence of active smoking among the various COPD phenotypes; the secondary objective was to determine the relationships between the smoking habit, COPD phenotypes, and major demographic and clinical variables, such as quality of life, disease severity, and presence of comorbidities.

\section{Patients and methods Study design and sample}

This was an observational, cross-sectional, multicenter study performed in Pulmonology departments and other specialist units (Internal Medicine, Family and Community Medicine, and Occupational Medicine) throughout Spain. The aim of this study was to determine the prevalence and characteristics of the 4 COPD phenotypes established by GesEPOC $^{3}$ in Spain. Each investigator was requested to include the first 6-8 unselected (consecutive) patients that fulfilled the selection criteria during the 90-day recruitment period. The study was approved by the Clinical Research Ethics Committee of the Hospital San Pedro de Alcántara in Cáceres, and patients gave written informed consent before participating. In this study, we examined the rates of active smoking and its relationship with COPD phenotype and factors influencing disease prognosis (severity, comorbidities, and quality of life). Patients were included if they were over the age of 35 years and had a clinical and functional diagnosis of COPD according to Global Initiative for Chronic Obstructive Lung Disease (GOLD) or GesEPOC criteria at least 6 months before participation in the study. Patients with symptoms of COPD exacerbation or who had had an exacerbation within the previous 6 weeks which could interfere with their perception of quality of life and functional status, those with any type of chronic respiratory disease other than COPD, or who had difficulty reading or understanding the study questionnaires were excluded from participation.

\section{Sociodemographic and clinical variables}

Each investigator was trained in the study procedures and questionnaires and used a case report form (CRF) to collect the demographic details of each patient and the clinical variables required for the study. The GesEPOC algorithm was used to determine COPD phenotype. ${ }^{3}$ This algorithm, classifies the phenotype according to the following rules: A) patients with $<2$ exacerbations in the previous year were classified as non-exacerbators; B) patients with a previous diagnosis of asthma were considered as ACOS; C) exacerbators with emphysema that have a clinical/radiological/ functional diagnosis of emphysema; and D) exacerbators who experienced cough with expectoration for $>3$ months of the year over 2 consecutive years were classified as exacerbators with chronic bronchitis. The schematic algorithm was provided to all the investigators (Figure 1).

Patients were asked about their smoking habit and were classified as nonsmokers, ex-smokers, and active smokers. COPD severity was measured using the BODEx index. ${ }^{20}$ Quality of life was assessed with the COPD Assessment Test (CAT). ${ }^{21}$ Finally, comorbidities present at the time of data collection were evaluated.

\section{Statistical analysis}

COPD phenotype distribution was calculated using a descriptive analysis, with percentages and binomial $95 \%$ confidence intervals (95\% CIs). Qualitative variables were compared using Fisher's exact test, and quantitative groups and variables were compared with the Student's $t$-test (for 2 groups) or the one-way analysis of variance (ANOVA) (for 3 or more groups). A logistic regression method was used to model the probability of being a smoker in relation to comorbidities (arrhythmia, coronary artery disease, heart failure, hypertension, dyslipidemia, diabetes mellitus, osteoporosis, and dementia), CAT score, serious exacerbations, and BODEx index. After stepwise analysis, the adjusted odds ratios (ORs) were calculated using multivariate logistic regression. Only significant associations are shown in the tables. All calculations were performed using the SAS statistical package version 9.4 for Windows, establishing a level of significance of 0.05 .

\section{Results}

A total of 268 respiratory medicine specialists, 177 primary care physicians, 34 internists, and 1 occupational 


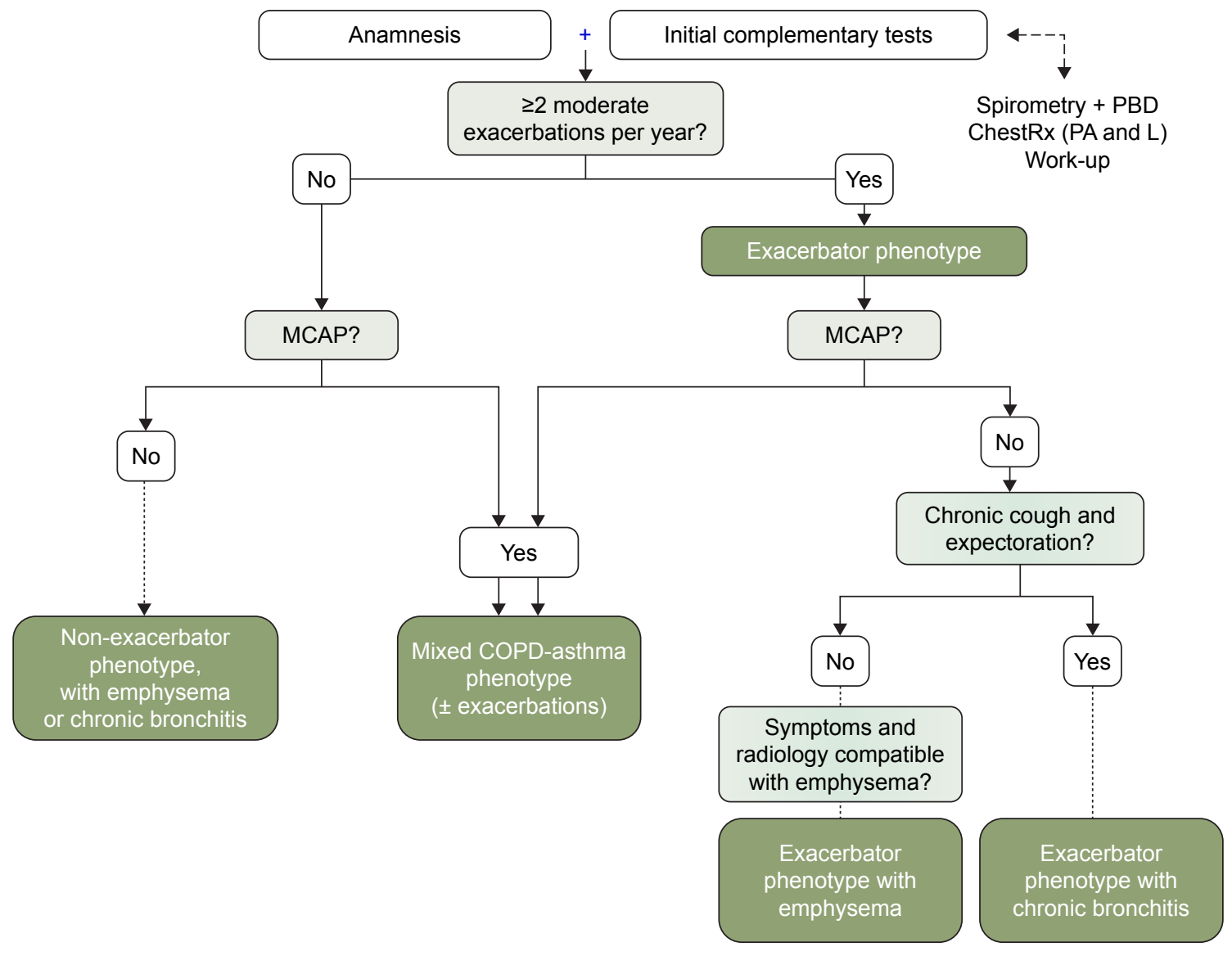

Figure I Diagnostic algorithm of the clinical phenotypes.

Note: Adapted from Miravitlles M, Soler-Cataluña JJ, Calle M, et al. Spanish COPD Guidelines (GesEPOC): Pharmacological treatment of stable COPD. Arch Bronconeumol. 2012;48(7):247-257, with permission from the Sociedad Española de Neumología y Cirugía Torácica (SEPAR). ${ }^{3}$

Abbreviations: COPD, chronic obstructive pulmonary disease; MCAP, mixed COPD-asthma phenotype; ACOS, asthma-COPD overlap syndrome; PBD, bronchodilator test.

medicine specialist participated in this study. They recruited 1,610 patients (see Tables 1 and S1 for patients' characteristics), predominantly men $(82.13 \%)$ with a mean age of 66.71 years (95\% CI: 66.24-67.19). Of these, $55.41 \%$ (95\% CI: 52.98-57.84) stated they were active smokers, with a smoking index of 65.02 pack-years (95\% CI: 59.62-71.41), and a mean forced expiratory volume in 1 second $\left(\mathrm{FEV}_{1}\right)$ (\%) of 54.70\% (95\% CI: 53.90-55.51). Seventy-one percent of patients had dyspnea grade $\leq 2$, a mean BODEx index of 2.75 (95\% CI: 2.65-2.85), and a mean CAT score of 22.04 (95\% CI: 21.43-22.66). Finally, 83.79\% had comorbidities, the most common being arterial hypertension $(62.90 \%)$ and diabetes mellitus (31.7\%).

With regard to phenotype distribution, $46.70 \%$ (95\% CI: 44.26-49.14) were classified as non-exacerbators, $14.53 \%$ (95\% CI: $12.81-16.25)$ as ACOS, $16.37 \%$ (95\% CI: 14.56 18.18 ) as exacerbators with emphysema, and $22.40 \%$ (95\% CI: 20.36-24.43) as exacerbators with chronic bronchitis (Figure 2). Significant differences were found in the distribution of sexes by phenotype; the most pronounced being in the ACOS phenotype, in which there were almost twice as many women as men $(21.7 \%$ vs $13.0 \%$, respectively, $P=0.002)$. Mean age among the phenotypes was significantly lower in the ACOS than that of exacerbators with chronic bronchitis (Table 2).

\section{Active smoking}

The frequency of active smoking by phenotype and its impact on quality of life, disease severity, and comorbidities were compared (Table 2). The group of nonsmokers accounted for only $2.9 \%$ of the total patient population; therefore, we decided to perform the remaining analyses on the basis of 2 groups only (active/nonsmokers + ex-smokers [nonactive smokers]). Even so, it is interesting to note that overall $9.1 \%$ of the female population had never smoked, whereas only $0.6 \%$ of all men had never smoked; this difference was statistically significant $(P<0.001)$. Active smokers were predominant among the exacerbator phenotypes with emphysema and with chronic bronchitis (58.91\% and 57.67\%, 
Table I Characteristics of the whole study population and stratification by smoking habit

\begin{tabular}{|c|c|c|c|c|}
\hline Variables & Total population & Active smokers & Non smokers & $P$-value \\
\hline \multicolumn{5}{|l|}{$\operatorname{Sex}(n, \%)$} \\
\hline Male & $1,314(82.1)$ & $738(56.2)$ & $574(43.8)$ & 0.39 \\
\hline Female & $286(17.9)$ & $152(53.3)$ & $133(46.7)$ & \\
\hline Age (years) & $66.7(66.2-67.2)$ & $67.0(66.4-67.7)$ & $66.3(65.6-67.0)$ & 0.12 \\
\hline BMI $\left(\mathrm{kg} / \mathrm{m}^{2}\right)$ & $27.9(27.6-28.1)$ & $27.7(27.4-28.0)$ & $28.1(27.7-28.4)$ & 0.10 \\
\hline Dyspnea grade & $1.8(1.7-1.8)$ & $1.8(1.8-1.9)$ & $1.7(1.6-1.8)$ & 0.003 \\
\hline \multicolumn{5}{|l|}{ Spirometry } \\
\hline FVC (L) & $2.5(2.4-2.6)$ & $2.5(2.4-2.6)$ & 2. $5(2.4-2.6)$ & 0.89 \\
\hline FVC (\%) & $73.5(72.7-74.2)$ & $73.4(72.3-64.4)$ & $73.6(72.7-74.2)$ & 0.75 \\
\hline $\mathrm{FEV}_{1}(\mathrm{~L})$ & $1.3(1.3-1.4)$ & $1.4(1.3-1.4)$ & $1.3(1.3-1.4)$ & 0.56 \\
\hline $\mathrm{FEV}_{1}(\%)$ & $54.7(53.9-55.5)$ & $54.2(53.1-55.4)$ & $55.3(54.1-56.5)$ & 0.18 \\
\hline $\mathrm{FEV}_{1} / \mathrm{FVC}$ & $55.4(54.7-56.0)$ & $55.2(54.3-56.1)$ & $55.5(53.9-55.5)$ & 0.64 \\
\hline CAT score & $22.0(21.4-22.7)$ & $20.5(\mid 9.6-21.4)$ & $23.3(22.5-24.1)$ & $<0.001$ \\
\hline BODEx & $2.7(2.6-2.8)$ & $2.8(2.7-3.0)$ & $2.7(2.5-2.8)$ & 0.15 \\
\hline Number of comorbidities & $2.0(1.9-2.1)$ & $2.1(2.0-2.2)$ & $1.9(1.8-2.0)$ & 0.07 \\
\hline
\end{tabular}

Note: Data presented as mean ( $95 \%$ confidence interval), unless otherwise stated.

Abbreviations: $\mathrm{Cl}$, confidence interval; BMI, body mass index; FVC, forced vital capacity; FEV , forced expiratory volume in I second; CAT, COPD assessment test; BODEx, body mass index, airflow obstruction, dyspnea and exacerbations.

respectively, $P=0.03$ ). The impact of active smoking on patients' quality of life was found to be significantly positive, according to the CAT scores $(20.51$ [95\% CI: 19.62-21.41] vs 23.33 [95\% CI: 22.50-24.15; $P<0.001]$ ). This relationship remained significant for each of the items making up the CAT scale. When this correlation was analyzed for the different phenotypes, we found that while active smokers consistently had a better CAT score, it was statistically significant only in the more common phenotypes, that is, non-exacerbators and exacerbators with chronic bronchitis. In contrast, when the relationship between active smokers and dyspnea severity was analyzed, active smokers were seen to have a significantly greater dyspnea grade (1.83 [95\% CI:

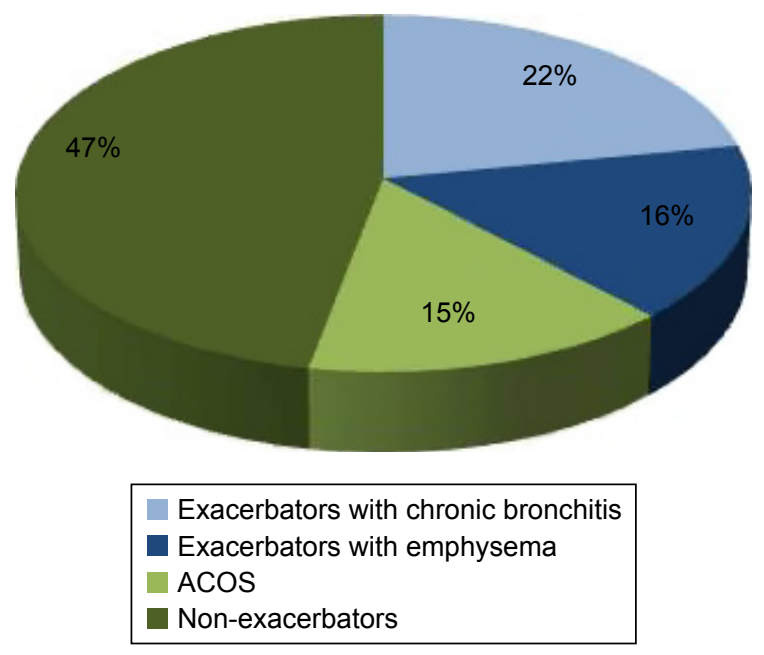

Figure 2 Distribution by COPD phenotype. Abbreviation: ACOS, asthma-COPD overlap syndrome.
$1.77-1.899$ ] vs 1.69 [95\% CI: $1.62-1.76] ; P=0.002)$. When this relation was assessed according to the different phenotypes, it was only maintained in the group of exacerbators with chronic bronchitis (2.21 [95\% CI: 2.09-2.33] vs 1.92 [95\% CI: $1.80-2.00] ; P=0.001)$. No differences were found in the BODEx score with respect to active smoking (2.82 [95\% CI: $2.68-2.96$ ] vs 2.67 [ $95 \%$ CI: $2.52-2.82$ ]; $P=0.73$ ). Finally, no differences were observed in the presence of comorbidities according to smoking habit, although active smokers tended to have a higher comorbidity burden; this difference was significant among patients classified as exacerbators with chronic bronchitis (Table 2).

Multivariate analysis showed that higher CAT scores were negatively associated, whereas BODEx score was positively associated with active smoking (Table 3 ). Among comorbidities, osteoporosis was the only one associated with the probability of an individual being a smoker $(\mathrm{OR}=1.61$, Wald 95\% CI: 1.45-2.26).

\section{Discussion}

The results of this study are derived from a larger study designed to describe phenotype distribution among patients with COPD throughout Spain. In comparison with other studies of Spanish series, ${ }^{22,23}$ we found that while the proportion of patients with ACOS in our cohort was still around $15 \%$, a greater proportion of patients were described as exacerbators (around $40 \%$ compared to $20 \%$ reported in other studies), and fewer were stable phenotypes ( $45 \%$ vs $65 \%$ ). It is difficult to determine the reason for this discrepancy as the definition used to characterize the exacerbator 
Table 2 Patient characteristics and COPD severity according to phenotype and smoking habit

\begin{tabular}{|c|c|c|c|c|}
\hline Variables & Non-exacerbators & Acos & $\begin{array}{l}\text { Exacerbators with } \\
\text { emphysema }\end{array}$ & $\begin{array}{l}\text { Exacerbators with } \\
\text { chronic bronchitis }\end{array}$ \\
\hline \multicolumn{5}{|l|}{$\operatorname{Sex}(n, \%)$} \\
\hline Male & 618 (47.9) & $167(13.0)$ & $209(16.2)$ & 296 (22.9) \\
\hline Female & $117(42.2)$ & $60(21.7)$ & $48(17.3)$ & $52(18.8)$ \\
\hline Age (years) & $66.2(65.5-67.0)$ & $64.8(63.5-66.2)$ & $67.9(66.7-69.0)$ & $68.1(67.1-69.1)$ \\
\hline \multicolumn{5}{|l|}{ Spirometry } \\
\hline FVC (L) & $2.6(2.5-2.7)$ & $2.5(2.3-2.7)$ & $2.3(2.2-2.4)$ & $2.3(2.2-2.4)$ \\
\hline FVC (\%) & $74.4(73.3-75.5)$ & 75.1 (73.I-77.I) & $71.3(69.2-73.4)$ & 72.1 (70.4-73.7) \\
\hline $\mathrm{FEV}_{1}(\mathrm{~L})$ & $1.4(1.4-1.5)$ & $1.4(1.3-1.5)$ & I.I (I.I-I.2) & $1.3(1.2-1.3)$ \\
\hline $\mathrm{FEV}_{1}(\%)$ & $56.6(55.4-57.7)$ & $60.8(58.8-62.8)$ & $46.6(44.6-48.6)$ & $52.6(50.9-54.2)$ \\
\hline $\mathrm{FEV}_{1} / \mathrm{FVC}$ & $56.0(55.1-56.9)$ & $60.0(58.4-61.7)$ & $49.3(47.6-51.0)$ & $55.3(54.0-56.6)$ \\
\hline \multicolumn{5}{|l|}{ Smoking habit (n, \%) } \\
\hline Active smokers & $40 \mathrm{I}(54.6)$ & II 2 (48.9) & $152(58.9)$ & $203(57.7)$ \\
\hline Non-active smokers & $334(45.4)$ & $117(51.1)$ & $106(4 I .1)$ & $149(42.3)$ \\
\hline \multicolumn{5}{|l|}{ Dyspnea grade } \\
\hline Active smokers & $1.5(1.4-1.6)$ & $1.7(1.5-1.9)$ & $2.3(2.2-2.5)$ & $2.2(2 . I-2.3)^{\mathrm{a}}$ \\
\hline Non-active smokers & $1.4(1.3-1.5)$ & $1.6(1.5-1.8)$ & $2.3(2.1-2.4)$ & $1.9(1.8-2.0)$ \\
\hline \multicolumn{5}{|l|}{ CAT score } \\
\hline Active smokers & $16.6(15.4-17.8)^{\mathrm{a}}$ & $24.0(22.1-26.5)$ & $24.6(22.7-26.5)$ & $23.5(21.4-25.7)^{\mathrm{a}}$ \\
\hline Non-active smokers & $20.0(|8.9-2| .1)$ & $25.3(23.4-27.2)$ & $26.8(24.7-28.9)$ & $26.8(25.0-28.6)$ \\
\hline \multicolumn{5}{|l|}{ BODEx } \\
\hline Active smokers & $2.1(1.9-2.3)$ & $2.2(1.8-2.6)$ & $4.2(3.9-4.6)$ & $3.5(3.2-3.8)$ \\
\hline Non-active smokers & $2.0(1.8-2.2)$ & $2.3(2.0-2.7)$ & $4.3(4.0-4.7)$ & $3.2(2.9-3.5)$ \\
\hline \multicolumn{5}{|l|}{ Number of comorbidities } \\
\hline Active smokers & $1.7(1.6-1.9)$ & $2.1(1.9-2.3)$ & $2.1(1.4-2.4)$ & $2.7(2.5-2.9)^{\mathrm{a}}$ \\
\hline Non-active smokers & $1.6(1.4-1.7)$ & $2.1(1.8-2.3)$ & $2.5(1.9-2.4)$ & $2.4(2.2-2.6)$ \\
\hline
\end{tabular}

Notes: a $P<0.05$ between active and non-active smokers in each phenotype category. Data presented as mean ( $95 \%$ confidence interval), unless otherwise stated. Abbreviations: $\mathrm{Cl}$, Confidence Interval; ACOS, asthma-COPD overlap syndrome; CAT, COPD assessment test; BODEx, body mass index, airflow obstruction, dyspnea and exacerbations; $\mathrm{FEV}_{1}$, forced expiratory volume in I second; FVC, forced vital capacity.

phenotype was the same in all studies (presence of at least 2 exacerbations in the last year or 1 hospitalization for acute exacerbation). The difficulty in precisely defining "exacerbation" may have contributed to this discrepancy. Evidence shows that exacerbations are often underreported because many patients with COPD may have difficulty in recognizing their symptoms as exacerbation, and accordingly, tend not to report them. ${ }^{24,25}$ Langsetmo et al, for example, evaluated the incidence of reported and unreported exacerbations in

Table 3 Factors associated with active smoking in the multivariate analysis

\begin{tabular}{llll}
\hline Variables & OR & $\mathbf{9 5 \% ~ C l}$ & P-value \\
\hline CAT (II-20 vs 0-10) & I.I4I & $0.769-1.693$ & $0.5 \mathrm{I}$ \\
CAT (2I-30 vs 0-10) & 0.700 & $0.472-1.038$ & 0.08 \\
CAT (3I-40 vs 0-10) & $0.30 \mathrm{I}$ & $0.187-0.487$ & $<0.00 \mathrm{I}$ \\
BODEx (3-4 vs 0-2) & $\mathrm{I} .202$ & $0.914-1.58 \mathrm{I}$ & 0.19 \\
BODEx (5-6 vs 0-2) & $\mathrm{I} .637$ & $1.15 \mathrm{I}-2.328$ & 0.006 \\
BODEx ( $\geq 7$ vs 0-2) & $2.05 \mathrm{I}$ & $\mathrm{I} .03 \mathrm{I}-4.080$ & 0.040 \\
Osteoporosis (yes vs no) & $\mathrm{I} .610$ & $\mathrm{I} .145-2.265$ & 0.006 \\
\hline
\end{tabular}

Abbreviations: $\mathrm{OR}$, odds ratio; $\mathrm{Cl}$, confidence interval; $\mathrm{CAT}$, COPD assessment test; BODEx, body mass index, airflow obstruction, dyspnea and exacerbations. a cohort of 421 patients with COPD and showed that less than one third of the exacerbations were reported, being that the number of symptoms at onset was the most important predictor of reporting. ${ }^{24}$ However, Hurst et al, in one of the largest studies conducted to determine susceptibility to exacerbations in stable patients with COPD over a period of 3 years, established that the incidence of exacerbations was $22 \%$ in patients with moderate COPD, rising to $47 \%$ in severe cases. ${ }^{25}$ According to the study authors, this incidence would have been much greater if untreated exacerbations had been computed along with treated events. In any case, the clinical implication of these results could be important. An action plan to help patients recognize changes in their symptoms, to implement self-care, and to self-initiate prescription in the event of an exacerbation has been suggested as a promising strategy. ${ }^{26}$

Existing evidence shows not only that smoking is the primary etiological cause of COPD, but also that it can also lead to faster decline in lung function if the habit continues; even so, the proportion of smokers among patients with COPD remains higher than among the general population. ${ }^{27}$ 
Recent studies performed in the USA found smoking rates between 35\% and $45 \%$ among adult patients with COPD. ${ }^{28,29}$ In our series, the prevalence of active smokers is $55 \%$, contrasting with reports recently published in Spain that set it at about $25 \%{ }^{22,23}$ Perhaps these differences reflect differences in data collection methods. Different ways of classifying a smoker as active may have a significant influence on the results of studies conducted in these patients, and hinder comparison among the different papers. ${ }^{30}$ However, a good level of agreement has been shown between smoking statuses based on self-reported and serum cotinine measurements. ${ }^{31}$ In any case, the proportion of active smokers among patients with COPD is still unacceptably high, particularly when we consider that one of the key objectives established by GOLD guidelines in the management of these patients is smoking cessation. ${ }^{1}$

Results on smoking and phenotype distribution among patients with COPD show that a significantly higher proportion of patients with exacerbator phenotype are active smokers. Previous data indicate that patients with greater susceptibility to viral infections are more prone to exacerbations, and this susceptibility appears to be associated with their smoking habit. ${ }^{32}$ The viral load during acute exacerbations of COPD has been detected as significantly higher than in stable state..$^{33}$ Moreover, a recent study has demonstrated an upregulated expression of ICAM-1 (major receptor for $60 \%$ of human rhinoviruses and Haemophilus influenza, two major pathogens in COPD) in the respiratory tract of smokers and especially in the airway epithelium in subjects with chronic airflow obstruction. This finding could reinforce the relation between active smoking, viral infection, and frequency of exacerbations. ${ }^{34}$ However, conflicting data about this association still persists. For example, Hurst et al, ${ }^{25}$ in a study that evaluated the impact of certain factors (ie, demographic and clinical characteristics, lung function, and laboratory and biomarkers values) on susceptibility to exacerbations found that while there was some relationship between active smoking and susceptibility to exacerbations, this association disappeared after multivariate analysis, showing that the link was not independent and may have been influenced by interactions with other variables, such as previous exacerbations, disease severity, health status, history of gastroesophageal reflux, and white cell count. ${ }^{25}$ This discrepancy has also been observed in series recently published in Spain..$^{22,23}$ Although Miravitlles et al ${ }^{22}$ did report a higher rate of smoking among exacerbators, Cosio et $\mathrm{al}^{23}$ failed to identify such an association. In our series, patients over the age of 50 years, who were significantly heavier smokers, were predominant in these phenotypes, and this may have affected the results.

When the impact of smoking on patients' quality of life was analyzed, we were surprised to find that former smokers obtained a poorer CAT score. Moreover, the fact that the groups that smoked most, that is, older patients and exacerbators, reported a worse quality of life makes this finding even more difficult to understand. Although most studies have found an inverse relationship between smoking and quality of life, this has not always been the case. Some studies have found that while many smokers attempt to give up their habit, many others continue to smoke as they associate the habit with psychological well-being, relaxation, and relief of stress. ${ }^{18,19}$ These factors may lead to a mistaken perception of quality of life on the part of the patients themselves. Wijnhoven et al also observed that quality of life was positively affected by active smoking. These authors associated it with the fact that patients with a better perception of their disease (less symptomatic) may wait longer before quitting smoking than patients with more severe symptoms. ${ }^{35}$ These differences might perhaps not have been revealed if the dynamics of this variable over time had been evaluated. Shields et al in a longitudinal study that analyzed the dynamics of smoking cessation between former smokers and nonsmokers concluded that a relatively long period of time was needed before quitters achieved level of comfortable life similar to those of individuals who have never smoked. Thus, the authors assert that it is difficult to extract conclusions on these measurements from cross-sectional studies. ${ }^{15}$ Ståhl et al also failed to find differences in quality of life associated with smoking habit among patients with COPD and suggest that the degree of disease severity is a metric with greater impact in this entity. ${ }^{36}$ The discordance is deepened further by the fact that dyspnea severity is significantly associated with active smoking. Several studies have cast doubts on the equivalence between dyspnea grade and CAT score in the evaluation of disease involvement. ${ }^{37,38}$ Indeed, recent evidence shows that the isolated use of CAT as a tool to establish the impact and severity of COPD may be inappropriate, given the difficulty of establishing definite cutoff points for a sufficiently sensitive and specific classification of patients according to their severity.$^{39}$ Our results appear to support this premise. Finally, we should mention the limited representation among our series of nonsmokers, which prevented us from analyzing the influence of this population on the final results.

COPD is often associated with other diseases and a great deal has been written about the systemic effects of 
the disease itself and how these clearly increase pressure on health care resources and the risk of death. COPD was associated with other diseases in up to $80 \%$ of the patients in our series, the most common comorbidity being arterial hypertension; these data coincide with the findings of most previously published studies. ${ }^{40,41}$ When comorbidities were analyzed according to the use of tobacco, it was found that patients with osteoporosis were more likely to be active smokers. Osteoporosis has been recognized as one of the major noncardiovascular comorbidities associated with COPD, occurring at rates of $4 \%-59 \%$, depending on the diagnostic method employed. ${ }^{42}$ Many explanations have been given for this association, including age, sex, smoking habit, limited daily activity, chronic hypoxemia, or corticosteroid treatment. Smoking has consistently been associated with low bone density in healthy volunteers; ${ }^{43}$ therefore, it is unsurprising that this relationship is stronger in patients with COPD, in whom other factors also combine to raise the risk of developing osteoporosis. It is also interesting to note the relationship that has been established between the emphysema phenotype and an increased risk of osteoporosis suggests a common mechanism between these two conditions. ${ }^{43,44}$ We ourselves did not find any specific relationship between phenotypes and osteoporosis, although active smokers were more predominant in phenotypes in which this disease may occur (nonexacerbators and exacerbators with emphysema).

\section{Conclusion}

Our study provides a general overview of how smoking, phenotype, and prognostic factors, such as quality of life or comorbidities, are interwoven in a large sample of Spanish patients with COPD. Some disparity between our data and those derived from similar recently published series may be due to the limitations to which all studies of this kind are subject (cross-sectional, participation of different specialists). Nevertheless, the results underline the importance of active smoking in the characterization of the disease.

\section{Acknowledgments}

This study was funded by Grupo Ferrer (Barcelona, Spain). The authors would like to thank David Calbet for providing statistical analysis and Jose L Lorenzo for manuscript writing assistance.

\section{Disclosure}

The authors report no conflicts of interest in this work.

\section{References}

1. Rabe KF, Hurd S, Anzueto A, et al; Global Initiative for Chronic Obstructive Lung Disease. Global strategy for the diagnosis, management, and prevention of chronic obstructive pulmonary disease: GOLD executive summary. Am J Respir Crit Care Med. 2007;176(6): 532-555.

2. Han MK, Agustí A, Calverley PM, et al. Chronic obstructive pulmonary disease phenotypes. The future of COPD. Am J Respir Crit Care Med. 2010;182(5):598-604.

3. Miravitlles M, Soler-Cataluña JJ, Calle M, et al. Spanish COPD Guidelines (GesEPOC): Pharmacological treatment of stable COPD. Arch Bronconeumol. 2012;48(7):247-257.

4. World Health Organization. WHO report on the global tobacco epidemic 2015. Available from: http:/www.who.int/tobacco/global_report/2015/ en/. Accessed January 9, 2017.

5. Miravitlles M, Calle M, Soler-Cataluña JJ. Clinical phenotypes of COPD: identification, definition and implications for guidelines. Arch Bronconeumol. 2012;48(3):86-98.

6. Golpe R, Sanjuán López P, Cano Jiménez E, Castro Añón O, Pérez de Llano LA. Distribution of clinical phenotypes in patients with chronic obstructive pulmonary disease caused by biomass and tobacco smoke. Arch Bronconeumol. 2014;50(8):318-324.

7. Izquierdo-Alonso JL, Rodriguez-Gonzálezmoro JM, de Lucas-Ramos P, et al. Prevalence and characteristics of three clinical phenotypes of chronic obstructive pulmonary disease (COPD). Respir Med. 2013; 107(5):724-731.

8. Hunter LC, Lee RJ, Butcher I, et al. Patient characteristics associated with risk of first hospital admission and readmission for acute exacerbation of chronic obstructive pulmonary disease (COPD) following primary care COPD diagnosis: a cohort study using linked electronic patient records. BMJ Open. 2016;6(1):e009121.

9. Garcia-Aymerich J, Monso E, Marrades RM; EFRAM Investigators. Risk factors for hospitalisation for a chronic obstructive pulmonary disease exacerbation. EFRAM study. Am J Respir Crit Care Med. 2001; 164(6):1002-1007.

10. Miravitlles M, Guerrero T, Mayordomo C, Sánchez-Agudo L, Nicolau F, Segú JL. Factors associated with increased risk of exacerbation and hospital admission in a cohort of ambulatory COPD patients: a multiple regression analysis. The EOLO Study Group. Respiration. 2000; 67(5):495-501.

11. Bahadori K, FitzGerald JM, Levy RD, Fera T, Swiston J. Risk factors and outcomes associated with chronic obstructive pulmonary disease exacerbations requiring hospitalisation. Can Respir J. 2009;16(4): e43-e49.

12. Tillmann M, Silcock J. A comparison of smokers' and ex-smokers' health-related quality of life. J Public Health Med. 1997;19(3): 268-273.

13. Woolf SH, Rothemich SF, Johnson RE, Marsland DW. Is cigarette smoking associated with impaired physical and mental functional status? An office-based survey of primary care patients. Am J Prev Med. 1999; 17(2):134-137.

14. McClave AK, Dube SR, Strine TW, Mokdad AH. Associations between health-related quality of life and smoking status among a large sample of U.S. adults. Prev Med. 2009;48(2):173-179.

15. Shields M, Garner RE, Wilkins K. Dynamics of smoking cessation and health-related quality of life among Canadians. Health Rep. 2013; 24(2):3-11.

16. Holahan CK, Holahan CJ, North RJ, Hayes RB, Powers DA, Ockene JK. Smoking status, physical health-related quality of life, and mortality in middle-aged and older women. Nicotine Tob Res. 2013;15(3):662-669.

17. Taylor G, McNeill A, Girling A, Farley A, Lindson-Hawley N, Aveyard P. Change in mental health after smoking cessation: systematic review and meta-analysis. BMJ. 2014;348:g1151.

18. McEwen A, West R, McRobbie H. Motives for smoking and their correlates in clients attending Stop Smoking treatment services. Nicotine Tob Res. 2008;10(5):843-850. 
19. Fidler JA, West R. Self-perceived smoking motives and their correlates in a general population sample. Nicotine Tob Res. 2009;11(10): 1182-1188.

20. Soler-Cataluña JJ, Martínez-García MA, Sánchez LS, Tordera MP, Sánchez PR. Severe exacerbations and BODE index: two independent risk factors for death in male COPD patients. Respir Med. 2009;103(5): 692-699.

21. Jones PW, Harding G, Berry P, Wiklund I, Chen WH, Kline Leidy N. Development and first validation of the COPD Assessment Test. Eur Respir J. 2009;34(3):648-654.

22. Miravitlles M, Barrecheguren M, Román-Rodríguez M. Frequency and characteristics of different clinical phenotypes of chronic obstructive pulmonary disease. Int J Tuberc Lung Dis. 2015;19(8):992-998.

23. Cosio BG, Soriano JB, López-Campos JL, et al. Distribution and Outcomes of a Phenotype-Based Approach to Guide COPD Management: Results from the CHAIN Cohort. PLoS One. 2016;11(9):e0160770.

24. Langsetmo L, Platt RW, Ernst P, Bourbeau J. Underreporting exacerbation of chronic obstructive pulmonary disease in a longitudinal cohort. Am J Respir Crit Care Med. 2008;177(4):396-401.

25. Hurst JR, Vestbo J, Anzueto A, et al; Evaluation of COPD Longitudinally to Identify Predictive Surrogate Endpoints (ECLIPSE) Investigators. Susceptibility to exacerbation in chronic obstructive pulmonary disease. $N$ Engl J Med. 2010;363(12):1128-1138.

26. Nici L, Donner C, Wouters E, et al; ATS/ERS Pulmonary Rehabilitation Writing Committee. American Thoracic Society/European Respiratory Society statement on pulmonary rehabilitation. Am J Respir Crit Care Med. 2006;173(12):1390-1413.

27. Centers for Disease Control and Prevention. MMWR 2012;61(46): 938-943. Available from: https://www.cdc.gov/mmwr/preview/ mmwrhtml/mm6146a2.htm. Accessed January 9, 2017.

28. Schauer GL, Wheaton AG, Malarcher AM, Croft JB. Smoking prevalence and cessation characteristics among U.S. adults with and without COPD: findings from the 2011 Behavioral Risk Factor Surveillance System. COPD. 2014;11(6):697-704.

29. Cheruvu VK, Odhiambo LA, Mowls DS, Zullo MD, Gudina AT. Health-related quality of life in current smokers with COPD: factors associated with current smoking and new insights into sex differences. Int J Chron Obstruct Pulmon Dis. 2016;11:2211-2219.

30. Ryan H, Trosclair A, Gfroerer J. Adult current smoking: differences in definitions and prevalence estimates - NHIS and NSDUH, 2008. J Environ Public Health. 2012;2012:918368.

31. Jain RB. Comparative analysis of two tobacco surveillance questionnaires used in NHANES: accuracy of self-reported smoking status. Toxicol Environ Chem. 2016;98(1):137-148.
32. Cohen S, Tyrrell DA, Russell MA, Jarvis MJ, Smith AP. Smoking, alcohol consumption, and susceptibility to the common cold. Am J Public Health. 1993;83(9):1277-1283.

33. George SN, Garcha DS, Mackay AJ, et al. Human rhinovirus infection during naturally occurring COPD exacerbations. Eur Respir J. 2014; 44(1):87-96.

34. Shukla SD, Mahmood MQ, Weston S, et al. The main rhinovirus respiratory tract adhesion site (ICAM-1) is upregulated in smokers and patients with chronic airflow limitation (CAL). Respir Res. 017;18:6.

35. Wijnhoven HA, Kriegsman DM, Hesselink AE, Penninx BW, de Haan M. Determinants of different dimensions of disease severity in asthma and COPD: pulmonary function and health-related quality of life. Chest. 2001;119(4):1034-1042.

36. Ståhl E, Lindberg A, Jansson SA, et al. Health-related quality of life is related to COPD disease severity. Health Qual Life Outcomes. 2005; 3:56.

37. Jones PW, Adamek L, Nadeau G, Banik N. Comparisons of health status scores with MRC grades in COPD: implications for the GOLD 2011 classification. Eur Respir J. 2013;42(3):647-654.

38. Kim S, Oh J, Kim YI, et al. Differences in classification of COPD group using COPD Assessment Test (CAT) or modified Medical Research Council (mMRC) dyspnea scores: a cross-sectional analyses. $B M C$ Pulm Med. 2013;13:35.

39. Mittal R, Chhabra SK. GOLD classification of COPD: discordance in criteria for symptoms and exacerbation risk assessment. COPD. 2017; 14(1): $1-6$

40. Camiciottoli G, Bigazzi F, Magni C, et al. Prevalence of comorbidities according to predominant phenotype and severity of chronic obstructive pulmonary disease. Int J Chron Obstruct Pulmon Dis. 2016;11: 2229-2236.

41. Gershon AS, Mecredy GC, Guan J, Victor JC, Goldstein R, To T, Quantifying comorbidity in individuals with COPD: a population study. Eur Respir J. 2015;45(1):51-59.

42. Lehouck A, Boonen S, Decramer M, Janssens W. COPD, bone metabolism, and osteoporosis. Chest. 2011;139(3):648-657.

43. Papaioannou A, Kennedy CC, Cranney A, et al. Risk factors for low BMD in healthy men age 50 years or older: a systematic review. Osteoporos Int. 2009;20(4):507-518.

44. Bon J, Fuhrman CR, Weissfeld JL, et al. Radiographic emphysema predicts low bone mineral density in a tobacco-exposed cohort. Am J Respir Crit Care Med. 2011;183(7):885-890. 


\section{Supplementary materials}

Table SI Description of patient population included in the study

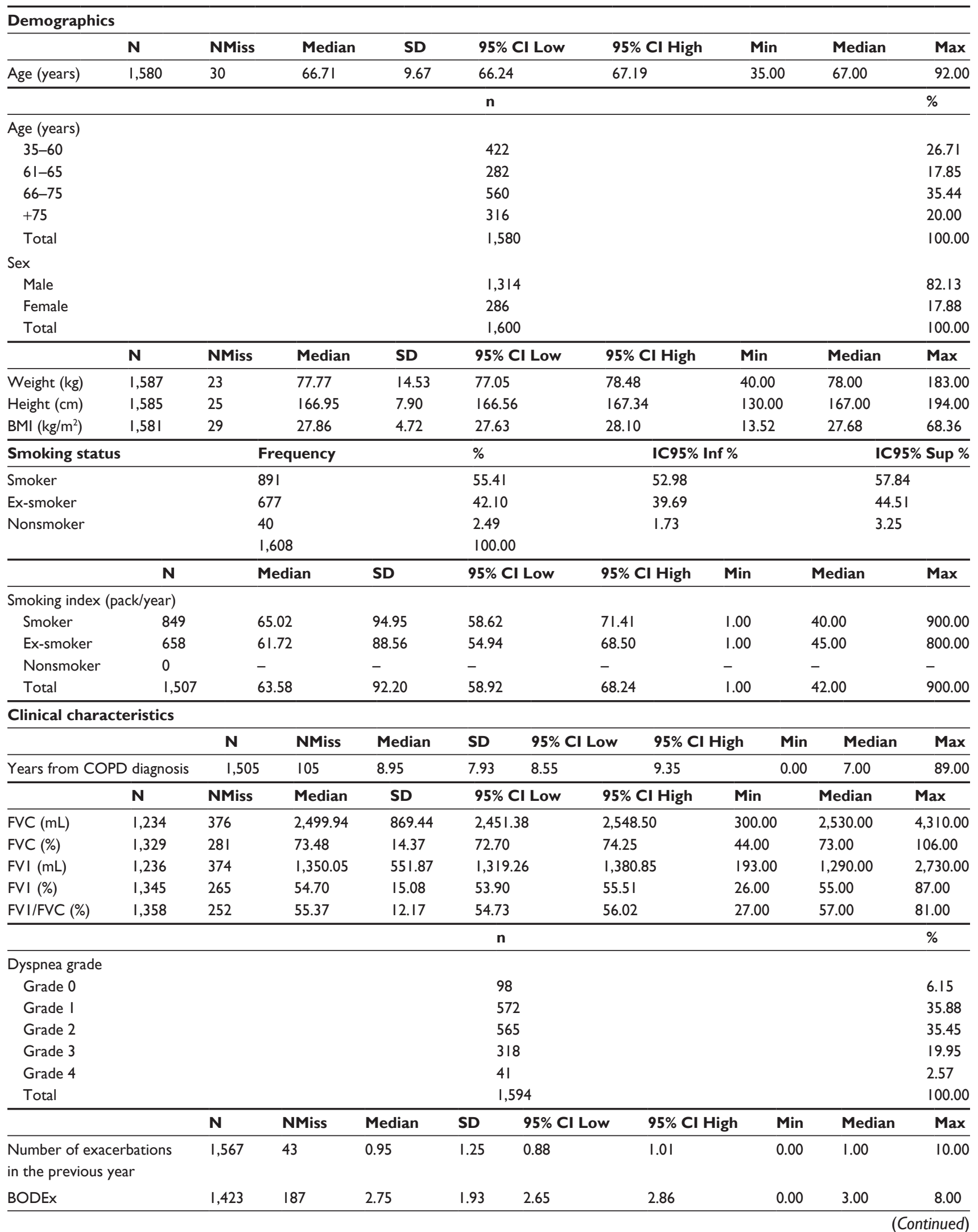


Table SI (Continued)

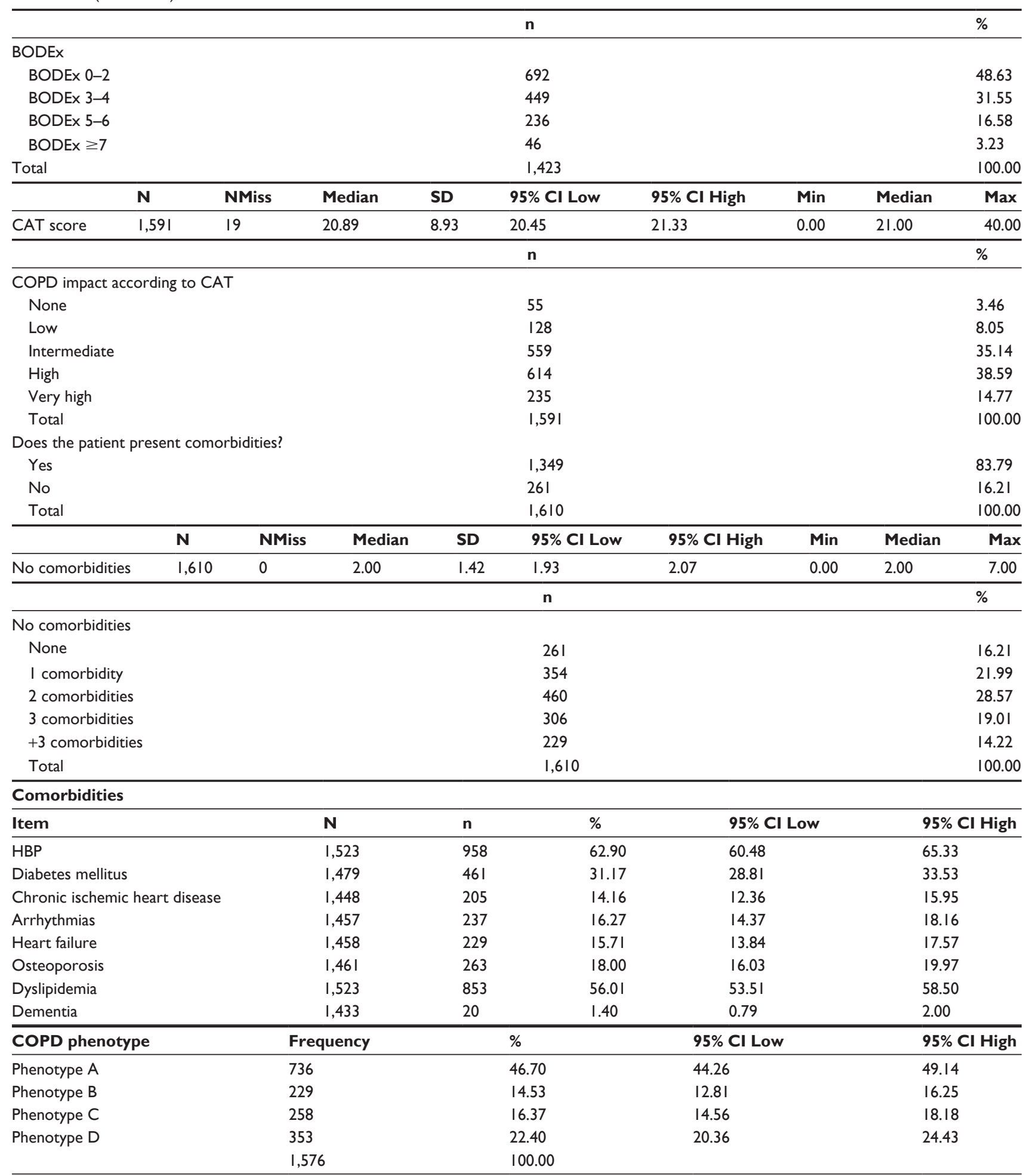

Abbreviations: BMI, body mass index; BODEx, body mass index, airflow obstruction, dyspnea and exacerbations; COPD, chronic obstructive pulmonary disease; CAT, COPD assessment test; FVC, forced vital capacity; FEV , forced expiratory volume in I second; HBP, high blood pressure; NMISS, number of missing entries. 
International Journal of COPD

\section{Publish your work in this journal}

The International Journal of COPD is an international, peer-reviewed journal of therapeutics and pharmacology focusing on concise rapid reporting of clinical studies and reviews in COPD. Special focus is given to the pathophysiological processes underlying the disease, intervention programs, patient focused education, and self management protocols. manuscript management system is completely online and includes a very quick and fair peer-review system, which is all easy to use. Visit $\mathrm{http}: / / \mathrm{www}$.dovepress.com/testimonials.php to read real quotes from published authors.

Submit your manuscript here: http://www.dovepress.com/international-journal-of-chronic-obstructive-pulmonary-disease-journal 